\title{
Fenofibric Acid
}

National Cancer Institute

\section{Source}

National Cancer Institute. Fenofibric Acid. NCI Thesaurus. Code C83804.

The active form of fenofibrate, a synthetic phenoxy-isobutyric acid derivate with antihyperlipidemic activity. 